\title{
Percepção Ambiental de Educadores do Campo e suas Influências no Processo Educacional em uma Escola do Município de Humaitá-AM
}

\section{Environmental Perception of Field Educators and their Influences on the Educational Process in School in the City of Humaitá-AM}

\section{Percepción Ambiental de dos Educadores de Campo y sus Influencias en el Proceso Educativo en una Escuela en la Ciudad de Humaitá-AM}

\author{
Albanice Souza dos Ramos ${ }^{1}$ \\ Larissa de Souza Saldanha ${ }^{2}$ \\ Eulina Maria Leite Nogueira ${ }^{3}$ \\ Renato Abreu Lima ${ }^{4}$
}

\begin{abstract}
Resumo
A percepção ambiental é uma atividade mental de interação do indivíduo com o meio, que pode ser definida como uma tomada de consciência do meio ambiente pelo ser humano. Dessa forma, esta pesquisa teve como objetivo analisar a percepção ambiental de educadores do campo e suas influências no processo educacional, na Comunidade Cristolândia em Humaitá-AM. A mesma foi desenvolvida através de uma pesquisa de campo com educadores da escola Municipal Antonieta Ataíde II da rede pública de ensino. Nesse sentido, os dados foram coletados por meio de entrevistas semiestruturadas, além da observação direta que se fez necessária para estabelecer sua relação com as questões ambientais e processos educacionais. Verificou-se que os educadores apresentam uma visão naturalista, ou seja, percebem o ambiente de forma natural, intocável com toda sua biodiversidade. Portanto, se faz necessária a elaboração de um programa de educação, a fim de propor estratégias que conduzam a uma maior conscientização ambiental.
\end{abstract}

Palavras-chave: Percepção ambiental. Preservação. Natureza. Educadores do campo.

\begin{abstract}
Environmental perception is a mental activity of interaction between the individual and the environment, which can be defined as an awareness of the environment by the human being. Thus, this research aimed to analyze the environmental perception of rural educators and their influences on the educational process, in the Cristolândia Community in Humaitá-AM. It was developed through a field survey with educators from the Antonieta Ataíde II Municipal school in the public school system. In this sense, data were collected through semi-structured interviews, in addition to the direct observation that was necessary to establish their relationship with environmental issues and educational processes. It was found that educators have a naturalistic view, that is, they perceive the environment in a natural way, untouchable with all its biodiversity. Therefore, it is necessary to develop an education program in order to propose strategies that lead to greater environmental awareness.
\end{abstract}

Keywords: Environmental perception. Preservation. Nature. Rural educators.

\section{Resumen}

La percepción ambiental es una actividad mental de interacción del individuo con el medio, que puede ser definida como una conciencia del entorno por parte del ser humano. Así, esta investigación tuvo como objetivo analizar la percepción ambiental de los educadores rurales y sus influencias en el proceso educativo, en la Comunidad

\footnotetext{
${ }^{1}$ Mestre pelo Programa de Pós-Graduação em Ciências Ambientais (PPGCA), Campus Vale do Rio Madeira, Instituto de Educação, Agricultura e Ambiente (IEAA) da Universidade Federal do Amazonas (UFAM)

${ }^{2}$ Mestre pelo Programa de Pós-Graduação em Ciências Ambientais (PPGCA), Campus Vale do Rio Madeira, Instituto de Educação, Agricultura e Ambiente (IEAA) da Universidade Federal do Amazonas (UFAM)

${ }^{3}$ Docente do Programa de Pós-Graduação em Ensino de Ciências e Humanidades (PPGECA/IEAA/UFAM)

${ }^{4}$ Docente do Programa de Pós-Graduação em Ciências Ambientais (PPGCA/IEAA/UFAM). E-mail: renatoal@ufam.edu.br
} 
Cristolândia de Humaitá-AM. Se desarrolló a través de una encuesta de campo con educadores de la escuela Municipal Antonieta Ataíde II del sistema escolar público. En este sentido, los datos fueron recolectados a través de entrevistas semiestructuradas, además de la observación directa que fue necesaria para establecer su relación con temas ambientales y procesos educativos. Se encontró que los educadores tienen una visión naturalista, es decir, perciben el medio ambiente de forma natural, intocable con toda su biodiversidad. Por tanto, es necesario desarrollar un programa educativo para proponer estrategias que conduzcan a una mayor conciencia ambiental.

Palabras clave: Percepción ambiental. Preservación. Naturaleza. Educadores rurales.

\section{Introdução}

Atualmente, cresce, em todo o globo, o número de movimentos ambientais, assim como, elevam-se os cuidados e a preocupação com o meio ambiente. O mundo tem se mostrado mais consciente de que o modelo de desenvolvimento econômico que outrora se apresentou. Porém, a produção de itens necessários ao homem está inteiramente associada à degradação do meio ambiente, causando-lhe impactos diretos. Tal cenário compromete a qualidade de vida e ameaça a sobrevivência no planeta (RODRIGUES; EICKHOFF, 2020).

Partindo desse pressuposto, a percepção ambiental pode ser definida como uma tomada de consciência, por parte dos indivíduos, sobre o meio ambiente em que se encontram inseridos, aprendendo a respeitar, proteger e cuidar da melhor forma possível (CARVALHO; GILPÉREZ, 2011).

Diante disso, Rodrigues; Eickhoff (2020) elucida que a percepção ambiental consiste na forma como o ser humano compreende o meio ambiente, observando a relação do homem com o ambiente natural é uma preocupação pertinente ao quadro ambiental e social.

O estudo da percepção ambiental de uma comunidade configura-se em uma ferramenta essencial para a compreensão acerca de comportamentos vigentes, bem como para o planejamento de ações que promovam a sensibilização e o desenvolvimento de posturas éticas e responsáveis perante o meio ambiente.

O interesse pela temática do estudo surgiu em virtude de experiências vivenciadas a partir do momento que a primeira autora passou a fazer parte do quadro de professores da escola Antonieta Ataíde II e do contato de forma direta com a comunidade local. No contexto de convivência com essa comunidade, a referida autora percebeu que a aplicabilidade de projetos e/ou atividades relacionadas ao meio ambiente poderiam minimizar ações antrópicas, resultando num aprendizado sobre a forma correta de utilizar os recursos naturais, sem agredir totalmente o meio em que se vive.

Nesse contexto, a presente pesquisa busca compreender a percepção ambiental que os educadores do campo possuem sobre meio ambiente e como se dá essa relação com a cultura e educação, pois a relação do homem com o ambiente natural é uma preocupação pertinente ao quadro ambiental, econômico e social de qualquer sociedade, nos dias atuais. Com isso, este trabalho teve como objetivo analisar a percepção ambiental de educadores do campo e suas influências no processo educacional na comunidade Cristolândia em Humaitá-AM.

\section{Material e Métodos}

A metodologia aplicada neste estudo buscou fornecer os instrumentos necessários para uma pesquisa em uma abordagem qualitativa. A mesma fundamentou-se nesse tipo de abordagem, levando em consideração as suposições de problemáticas de grupos sociais, não só de forma quantitativa, mas, sim, com fenômenos produzidos pela ação humana e a partir de fenômenos que produziram reflexões sobre a realidade estudada.

Sendo assim, a pesquisa que resultou neste artigo foi realizada na Escola Municipal Antonieta Ataíde II, rede municipal de ensino, localizada na comunidade de Cristolândia, na 
BR 319, distante a $55 \mathrm{~km}$ de Humaitá-AM. Os sujeitos da pesquisa foram oito professores que atuam na referida escola.

Para nortear e embasar este trabalho científico privilegiou-se como procedimento metodológico a revisão bibliográfica por meio de livros, artigos científicos, teses e dissertações, utilizando as seguintes palavras-chaves: Percepção ambiental, Preservação, Natureza, Educadores do campo.

Outro procedimento utilizado foi à pesquisa documental, que se fez necessária para a compreensão da Educação do Campo, visto que a problemática sobre o meio ambiente vem sendo registrada nos documentos oficiais que regem a educação. A análise documental foi realizada por meio de documentos disponibilizados pela Secretaria Municipal de Educação (SEMED), órgão público que é responsável pela educação no Município de Humaitá, Amazonas, além de leis e normas referentes à educação do campo e ambiental.

Assim, a pesquisa bibliográfica torna-se importante para a etapa inicial da investigação proposta, pois consiste em reunir as informações e dados que servirão de base para a construção da investigação proposta a partir de determinado tema.

Após a revisão bibliográfica e pesquisa documental, partiu-se para a coleta de dados por meio de entrevista com perguntas semiestruturadas, realizada com os educadores que aceitaram participar desta pesquisa, além da observação direta.

Todavia, essa foi uma etapa de suma importância na realização da pesquisa, pois teve a finalidade de coletar os dados diretamente no lócus do estudo; esse tipo de abordagem visa integrar a pesquisa bibliográfica e documental para a construção do objeto pesquisado, com mais aprofundamento do conhecimento (FÁVERO; NEVES, 2013).

Para a realização da pesquisa de campo, primeiramente, foi solicitada autorização junto à SEMED e, posteriormente, junto à direção da escola Municipal Rural Antonieta Ataíde II. Após a autorização da escola, logo em seguida, foi submetida ao Comitê de Ética em Pesquisa (CEP) para a devida análise e autorização. Após aprovação no Comitê de Ética, o projeto foi apresentado aos educadores para conhecimento e realização de esclarecimento que se fez necessário. Na oportunidade foi apresentado o TCLE, que os educadores leram e ficaram cientes do que tratava a pesquisa, diante disso, concordaram em participar e assinaram o termo ${ }^{5}$.

Durante o período de permanência na comunidade foram realizadas as entrevistas e a observação direta com os educadores dentro do contexto escolar. Nesta fase, foram utilizados o caderno de campo, gravador e câmeras fotográficas, cujo intuito foi registrar os acontecimentos do cotidiano desses educadores em relação às questões ambientais, suas atitudes e seu envolvimento com a natureza.

Após aprovação final do CEP, iniciou-se a aplicação das entrevistas semiestruturadas contemplando questões relativas aos dados socioeconômicos dos docentes, que foram necessários para melhor caracterização dos participantes.

A coleta de dados ocorreu por meio de entrevistas, através das visitas ao local de estudo, autorizadas pelo gestor da escola, representante da comunidade e professores, onde foram feitos todos os esclarecimentos e assinados os devidos documentos relevantes para a realização da pesquisa, sendo agendada uma data e horário que fossem mais convenientes a todos os participantes e o período de realização da coleta de dados em campo foi do dia 10/12 a 17/12 de 2018.

\footnotetext{
5 Este estudo foi submetido e aprovado pelo Comitê de Ética em Pesquisa (CEP) com número CAAE: 01039318.3.0000.5020. Os entrevistados não tiveram seus nomes ou fotos divulgadas sem sua autorização, pois a pesquisa está em total consonância com os critérios bioéticos preconizados pela Resolução/CNS N 466/2012 (BRASIL, 2012a), a respeito de estudos envolvendo seres humanos.
} 
Outro instrumento utilizado nesta pesquisa foi à observação direta, etapa da investigação que consistiu em construir elementos que permitam fundamentar o objeto de estudo.

Levando em consideração a pesquisa a partir da abordagem qualitativa, elencam-se as seguintes técnicas que serviram de auxílio na captação de dados para a pesquisa: considerando a natureza da investigação desta pesquisa, optou-se pela gravação das entrevistas em áudio, visto que é uma técnica eficaz para uma melhor compreensão dos dados coletadas. As entrevistas foram realizadas mediante a autorização dos participantes.

A elaboração dos tópicos da entrevista foi embasada em levantamentos bibliográficos sobre o assunto, na experiência pessoal de seis anos no trabalho com educação (da primeira autora), e nas discussões com profissionais de diferentes áreas do conhecimento, procurando atender os objetivos relacionados deste trabalho (BONI; QUARESMA, 2005).

A entrevista foi dividida em dois blocos. O bloco I, denominado Perfil dos Professores, possibilitou o delineamento dos perfis dos educadores participantes deste estudo, com o intuito de conhecer seus dados pessoais e suas experiências na área da educação, entre outros. No bloco II, denominado Percepção Ambiental dos Educadores, trabalharam-se as questões, de forma subjetiva, a fim de contemplar informações em dois enfoques: percepção do meio ambiente e seus recursos e a percepção da relação ser humano e meio ambiente. No primeiro enfoque, foram abordadas questões sobre água, solo, ar, florestas, problemas ambientais, utilização de recursos naturais, papel do poder público e fauna. Enquanto que, no segundo enfoque, abordouse o processo educativo da escola, a interdisciplinaridade para seus alunos e comunidade.

Essa experiência, juntamente com a preocupação das questões ambientais foi presenciada no município de Humaitá-AM, impulsionando a pesquisadora a investigar a percepção dos educadores do campo sobre o meio ambiente. Diante disso, após coletar os dados por meio das entrevistas, todas foram digitadas na íntegra, sem cortes nos depoimentos dos entrevistados, para que assim a transcrição ocorresse da forma mais fidedigna possível, ou seja, sem interrupções de informações que foram necessárias para a construção dessa pesquisa.

Após concluir essas etapas, os dados coletados foram organizados e analisados de forma crítica, por meio de análise textual discursiva (ATD). Em seguida, iniciou-se a análise dos dados com o objetivo de identificar a percepção apresentada pelos educadores.

Para os dados coletados no bloco II utilizou-se a técnica da ATD, que se caracteriza como "uma abordagem de análise de dados que transita entre duas formas consagradas de análise na pesquisa qualitativa que são a Análise de Conteúdo e a Análise de Discurso" (MORAES; GALIAZZI, 2016, p.118), visando, assim, à construção de respostas aos questionamentos propostos.

Sousa; Galiazzi (2017) afirma que a ATD se produz a partir da unitarização, que consiste na produção de unidades de significado a partir da exigência do método, e esse é, portanto, um modo operativo de desencadear a lida com o material empírico, mas o fenômeno exige do pesquisador uma ampliação do operativo em direção ao modo perceptivo e intuitivo na análise. Esse método, se por um lado pode chegar a ser mais aberto e intuitivo na produção de categorias, por outro, pode prender o pesquisador a critérios para garantir a cientificidade.

Portanto, neste estudo a ATD foi elaborada sobre as entrevistas coletadas. Para tanto, na transcrição, descreveram-se na íntegra os discursos dos educadores apresentados nas entrevistas, sem nenhum corte, correções ou interpretações iniciais, cujo objetivo foi preservar a fala dos participantes para serem analisadas de acordo com as categorias que foram construídas a posteriori.

\section{Resultados e Discussão}




\subsection{Perfil pessoal e acadêmico dos educadores participantes da pesquisa}

Os educadores da Escola Municipal Rural Antonieta Ataíde II que atuam nas diversas modalidades de ensino (Educação Infantil, Ensino Fundamental I e II e EJA), apresentam formação em nível de graduação e pós-graduação, nas seguintes áreas: Pedagogia, Letras e Normal Superior, atendendo a uma demanda de 105 alunos.

Todos os professores entrevistados são procedentes da área urbana e possuem formação acadêmica em nível superior, apenas dois deles não possuem pós-graduação, os mesmos afirmam que trabalham a temática ambiental em suas aulas, porém a falta de materiais pedagógicos e projetos voltados para a preservação do meio ambiente acabam dificultando o trabalho em sala de aula, e por esse motivo, apresentam dificuldades em abordar essa temática de forma interdisciplinar e mais profunda.

Para compreender o quadro de professores procurou-se criar o perfil dos professores que desenvolve atividades na referida escola como forma de relacionar sua idade, formação acadêmica, especialização, regime de trabalho, tempo de atuação e carga horária (Quadro 01).

\begin{tabular}{|c|c|c|c|c|c|c|c|}
\hline Prof & Gênero & Idade & $\begin{array}{l}\text { Formação } \\
\text { Acadêmica }\end{array}$ & Pós-Graduação & $\begin{array}{l}\text { Regime de } \\
\text { Trabalho }\end{array}$ & $\begin{array}{l}\text { Tempo de } \\
\text { Atuação }\end{array}$ & $\begin{array}{l}\text { Carga } \\
\text { Horária }\end{array}$ \\
\hline P1 & Masc. & 45 & $\begin{array}{l}\text { Normal } \\
\text { Superior }\end{array}$ & $\begin{array}{l}\text { Alfabetização e } \\
\text { Linguagem }\end{array}$ & Efetivo & 20 Anos & $60 \mathrm{~h}$ \\
\hline $\mathbf{P 2}$ & Fem. & 36 & Pedagogia & $\begin{array}{l}\text { Psicopedagogia/ } \\
\text { Metodologia }\end{array}$ & Efetivo & 18 Anos & $20 \mathrm{~h}$ \\
\hline P3 & Fem. & 39 & Pedagogia & Psicopedagogia & Efetivo & 2 Anos & $20 \mathrm{~h}$ \\
\hline P4 & Masc. & 37 & Letras & Não possui & Seletivo & 2 Anos & $20 \mathrm{~h}$ \\
\hline P5 & Masc. & 54 & Normal superior & Filosofia da História & Efetivo & 22 Anos & $40 \mathrm{~h}$ \\
\hline P6 & Fem. & 35 & Pedagogia & Psicopedagogia & Efetivo & 5 Anos & $40 \mathrm{~h}$ \\
\hline P7 & Fem. & 26 & Pedagogia & Psicopedagogia & Efetivo & $\begin{array}{l}1 \text { Ano e } 5 \\
\text { meses }\end{array}$ & $20 \mathrm{~h}$ \\
\hline P8 & Fem. & 34 & Letras & Não Possui & Seletivo & 6 Anos & $20 \mathrm{~h}$ \\
\hline
\end{tabular}

Quadro 01 - Perfil dos professores da Escola Municipal Rural Antonieta Ataíde II Fonte: elaborado pelas autoras

Como se pode perceber, de acordo com o Quadro 01, foram entrevistados oito professores, sendo cinco do sexo feminino e três do sexo masculino. Por questões éticas, foram identificados com um código de acordo com a função que exercem na escola, associado a um número que corresponde à ordem das entrevistas $(\mathrm{P} 1, \mathrm{P} 2, \mathrm{P} 3 \ldots)$. Verificou-se que todos os professores possuem formação superior, seis professores possuem pós-graduação e apenas dois não possuem exatamente os que se encontram no regime de trabalho de processo seletivo.

Apesar de a escola apresentar uma realidade diferente da maioria das escolas do campo do Amazonas, com grande parte dos professores efetivos, não se pode dizer que isso configura um fator importante, pois todos os professores ministram aulas de disciplinas diferentes de sua formação acadêmica, o que pode comprometer o processo de ensino-aprendizagem dos alunos. A carga horária varia de 20 à $60 \mathrm{~h}$ de trabalhos semanais na escola. Essa prática de ministrar disciplina para a qual o professor não possui formação é comum nas escolas do campo, fato este que na maioria das vezes, torna o trabalho do professor difícil e, consequentemente, refletese na aprendizagem dos alunos. A formação docente na educação do campo é retratada, no estudo de Bezerra; Silva (2018), como uma consequência da política educacional. O Quadro 02 
mostra, de forma detalhada, o perfil dos professores da escola Municipal Rural Antonieta Ataíde II.

\begin{tabular}{|c|c|c|}
\hline Professor & Disciplinas & Modalidade \\
\hline $\begin{array}{c}\text { P1 } \\
\text { Normal } \\
\text { Superior }\end{array}$ & $\begin{array}{c}\text { História, Matemática, Educação Física, Arte e } \\
\text { Ensino Religioso }\end{array}$ & EJA \\
\hline $\begin{array}{c}\text { P2 } \\
\text { Pedagogia }\end{array}$ & Todas as disciplinas & $4^{\circ}$ e $5^{\circ}$ Ano \\
\hline \multirow[b]{2}{*}{$\begin{array}{c}\text { P3 } \\
\text { Pedagogia }\end{array}$} & Todas as disciplinas & Ed. Infantil \\
\hline & $\begin{array}{l}\text { Ensino Religioso, Língua Portuguesa, e Língua } \\
\text { Inglesa. }\end{array}$ & $6^{\circ}$ ao $9^{\circ}$ Ano \\
\hline $\begin{array}{c}\text { P4 } \\
\text { Letras }\end{array}$ & $\begin{array}{c}\text { Ensino Religioso, Língua Portuguesa e Língua } \\
\text { Inglesa. }\end{array}$ & $6^{\circ}$ ao $9^{\circ}$ Ano \\
\hline \multirow{2}{*}{$\begin{array}{c}\text { P5 } \\
\text { Normal superior }\end{array}$} & Todas as disciplinas & $1^{\circ}$ ao $3^{\circ}$ Ano \\
\hline & Todas as disciplinas & EJA \\
\hline $\begin{array}{c}\text { P6 } \\
\text { Pedagogia }\end{array}$ & Reforço & $1^{\circ}$ ao $5^{\circ}$ Ano \\
\hline $\begin{array}{c}\text { P7 } \\
\text { Pedagogia } \\
\end{array}$ & Todas as disciplinas & $4^{\circ}$ e $5^{\circ}$ Ano \\
\hline $\begin{array}{c}\text { P8 } \\
\text { Letras }\end{array}$ & Matemática, Educação Física e Artes & $6^{\circ}$ ao $9^{\circ}$ Ano \\
\hline
\end{tabular}

Com relação ao tempo de serviço na educação, constatou-se que três professores possuem uma vasta experiência, apresentando mais de 18 anos de docência, e os demais com pouca experiência, sendo considerados professores iniciantes. Em conversa informal, constatou-se que os professores dessa escola não receberam nenhum tipo de formação específica para trabalhar com a educação do campo.

A luta da população do campo por uma educação de qualidade sempre esteve voltada para a preparação para o mercado de trabalho, além disso, prepara-los para exercer seu papel de cidadão social, onde seus direitos e deveres fossem respeitados, sendo assim capazes de compartilhar conhecimentos com direito a igualdade e democracia (RAMOS et al., 2021).

\subsection{Percepção ambiental de educadores do campo em Humaitá-AM e suas influências no processo educacional}

Para a realização das análises dos dados coletados, os mesmos foram organizados de acordo com a ordem das entrevistas. Nos dados coletados no bloco I - Perfil dos Professores, construiu-se um quadro para ter uma visão mais completa da formação, experiência, tempo de serviço, regime de trabalho e carga horária dos educadores (Quadro 01).

Ampliando-se a investigação ao analisar a fala dos entrevistados por meio da ATD, compreenderam-se como os educadores pensam e agem no mundo concreto em relação ao meio ambiente, bem como isso influência no processo educacional, levando-se em conta sua formação, condições sociais, históricas e ideológicas.

$\mathrm{Na}$ primeira fase, organizaram-se as respostas relacionando-as com o contexto em que os sujeitos da pesquisa se encontram inseridos. Nessa etapa, buscaram-se a compreensão dos discursos, identificando-se as diversas expressões recorrentes nas respostas apresentadas. Logo em seguida, as perguntas foram agrupadas em três categorias distintas (Meio Ambiente, 
Educação, Sustentabilidade), que foi resultado da criação de nuvem de palavras, de acordo com sua frequência.

Para identificar as categorias, recorreu-se à utilização do programa Wordclouds.com que trabalha como um gerador de nuvem de palavras on-line, esse programa está disponível gratuitamente e serviu para criar um gráfico que expressa o grau de frequência das palavras utilizadas. Nesse programa as palavras aparecem em diversas cores e tamanhos para indicar o que é mais e menos relevante no texto (Figura 01).

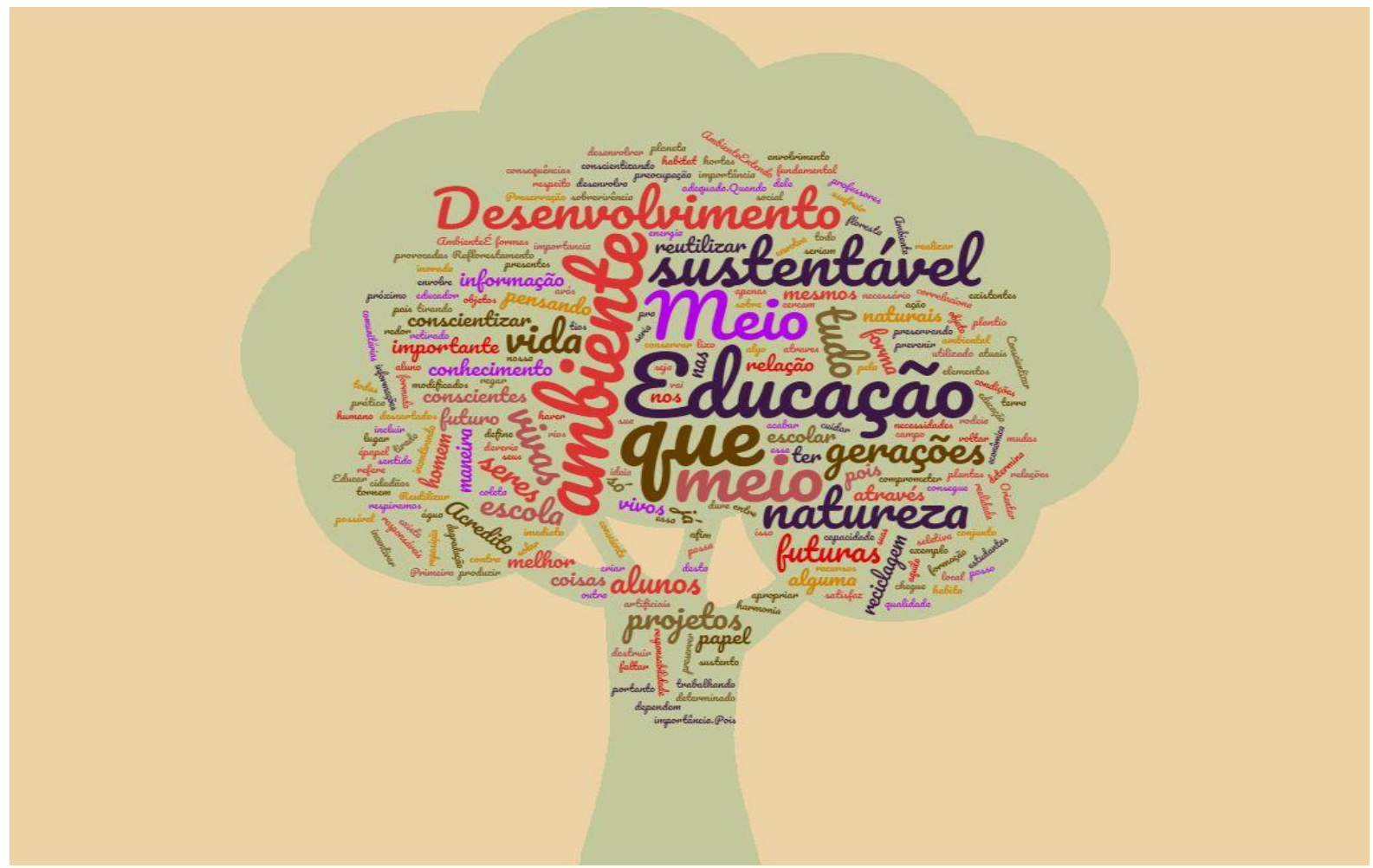

Figura 01 - Percepção Ambiental dos Professores

Fonte: elaborada pelas autoras usando o Wordclouds@

Para a realização da categorização, levaram-se em consideração os significados atribuídos pelos sujeitos desta pesquisa nas entrevistas que foram realizadas. A palavra que aparece com mais frequência é Desenvolvimento Sustentável, mas neste trabalho utilizou-se a categoria sustentabilidade. Durante o processo de análise, estabelecemos as categorias de acordo com as perguntas e o objetivo desta pesquisa.

Quanto se indagou sobre o que seria meio ambiente, observou-se que essa percepção está muito ligada à natureza, à floresta e ao ambiente natural, delineando-se uma perspectiva que projeta uma visão romântica da natureza.

\subsubsection{Categoria 1 - Meio ambiente}

Quando se indagou sobre o que os professores entendiam por meio ambiente, as respostas dos educadores demonstraram que relacionam o meio ambiente à natureza, ao desmatamento. No geral, não contextualizam os diferentes ambientes modificados pela ação humana. Apenas um informante estabeleceu uma relação nos ambientes modificados, como se constata nas falas seguintes, inseridas no relatório de transcrição.

Meio ambiente é tudo que está ao nosso redor, a natureza, os rios, a floresta, o ar que respiramos, tudo está ligado ao meio ambiente, portanto é a nossa vida (P4). 
Meio ambiente é tudo que nos rodeia, formado por elementos naturais e artificiais modificados (P2).

Meio ambiente é o local ou lugar que o ser habita (P5).

Preservação da natureza e o habitat dos seres vivos (P6) (RELATÓRIO DE TRANSCRIÇÃO, 2018, p. 74).

Conforme foi observado, os professores relacionam o termo meio ambiente somente ao meio natural, sem considerar a inter-relação do homem-natureza, considerando a natureza intocada, um lugar distante. Esse fato remete à importância de criar consciência de que a natureza é transformada pelo homem, seja numa escala menor e/ou maior, com possibilidade de recomposição ou a sua destruição total. Atualmente, a população utiliza os recursos naturais de forma predatória, sem avaliar os danos que a ação do homem pode causar ao meio ambiente e ao próprio ser humano.

Assim, o processo educativo, ao mesmo tempo em que constroi o ser humano como humano, constrói, também, a realidade na qual ele se objetiva como humano, constrói a humanidade. Se não trazemos, ao nascer, os instrumentos necessários para compreender as leis da natureza e da cultura, e não temos condições biológicas para que isso aconteça naturalmente, o processo de formação do ser humano é histórico e social, o que quer dizer intencionalmente dirigido, pelos próprios seres humanos em suas relações entre si e com o ambiente em que vivem (TOZONI-REIS; CAMPOS, 2014).

Diante disso, percebe-se que o grande desafio apresentado pelas escolas é conhecer o contexto cultural do aluno para que assim possa trabalhar de acordo com suas vivências, ou seja, trazer a realidade do aluno para sala de aula, para que assim ele possa sentir-se mais à vontade e poder compartilhar suas experiências e expressar seus conhecimentos prévios (RAMOS et al., 2021).

Considerem-se, por exemplo, o caso de um dos problemas ambientais que mais se destaca no município de Humaitá-AM, o descarte dos resíduos sólidos, que ocorre de forma irregular, ficando exposto ao céu aberto, fato que passa despercebido pelas autoridades locais, sem nenhum controle sanitário ou ambiental, visto que, além de causar sérios danos ao meio ambiente acaba comprometendo a saúde e o bem-estar da população, pois os lixões fornecem condições propícias para a proliferação de doenças (OLIVEIRA et al., 2016).

No entanto, são necessárias medidas urgentes que possam diminuir esses impactos que vem afetando o meio ambiente e a população, pois além dos gases que são liberados, à medida que o lixo vai se decompondo gera o chorume, sendo um líquido que contamina o solo e os lençóis freáticos em virtude dos compostos orgânicos e íons metálicos.

Outro questionamento realizado foi sobre a relação dos professores com a natureza. As respostas indicam que os professores se relacionam com a natureza de forma romântica, baseada no amor, na harmonia, no respeito e cuidado. Um professor apresentou certo nível de consciência ambiental, ao apontar que entende os danos que o uso descontrolado dos recursos naturais pode causar ao meio ambiente.

Particularmente harmoniosa. Pois, devido morar no sítio, tenho uma natureza como fonte de sobrevivência, pois é dela que consigo extrair uma parte de minha alimentação diária (P6).

Minha relação com a natureza é com muito respeito, procuro sempre fazer o melhor para com ela, pois preciso dela para sobreviver (P4).

Relação de extremo respeito, pois sei da sua importância para minha qualidade de vida, porém tenho consciência que poderia fazer mais para sua preservação (P7).

Muito natural, amigável tratando-a com respeito (P5).

Na medida do possível, procuro fazer a minha parte, selecionando o lixo, preservando o pouco de árvore que ainda existe (regando quando posso) e economizando água sempre reutilizando $\mathrm{p} /$ outras coisas, economizando energia e sempre que posso deixo 
o carro e utilizo a bicicleta a fim de diminuir os poluentes liberados no ar (P2) (RELATÓRIO DE TRANSCRIÇÃO, 2018, p. 78).

Constatou-se que a maioria dos professores apresenta uma visão muito romântica em relação ao meio ambiente, isso é um fator preocupante quando profissionais da educação apresentam pouco questionamento sobre a sua participação direta na construção de um mundo mais justo economicamente, social e ecologicamente. É necessário refletir sobre a forma de como a sociedade vem se apropriando dos bens naturais e transformando em produtos cada vez mais descartáveis, utilizando de fonte não renováveis de energia, se apropriando de recursos minerais de forma predatória causando danos aos rios, solo e floresta.

Durante a entrevista e na observação direta, presenciaram-se os problemas ambientais na comunidade e, por consequência, na escola. Nesse sentido, foi feito um questionamento aos professores sobre os problemas ambientais predominante na comunidade. Os professores e moradores da comunidade enfatizaram a falta de saneamento básico, pois não existe pavimentação das ruas, água tratada e nem rede de esgoto, além do problema do lixo.

Apesar de a comunidade Cristolândia apresentar um número pequeno de moradores, o problema do lixo é prevalente, visto que é possível encontrar lixo exposto a céu aberto e o município de Humaitá não disponibiliza atendimento para coletar esses resíduos. Pode-se confirmar essa situação por meio da fala de alguns entrevistados.

\begin{abstract}
Esse é um grande problema, na comunidade se depara em uma grande quantidade de lixo espalhado por todos os cantos, não tendo destino próprio. Por não ter coleta diariamente, as pessoas usam o meio mais fácil, enterrando ou queimando. A maioria desse lixo fica espalhado em céu aberto trazendo inúmeras consequências para a comunidade, mantendo em risco a própria saúde $(\mathrm{P} 1)$.

Percebo que nesta comunidade não existe coleta de lixo. Os moradores para se livrarem acabam queimando o lixo em seus quintais, e em outros casos, percebo que jogam lixo em qualquer lugar, o que pode ocasionar doenças para este lugar (P3).

Aqui onde trabalho um dos piores problemas ambientais encontrado é a questão do lixo, não existe local adequado para os resíduos e, muitas das vezes, são jogados as margens da BR ou ainda queimados sem nenhuma precaução (P4).

Ainda falta local apropriado para depositar o lixo. Precisa-se de um local (aterro sanitário) para o lixo que não fique a céu aberto, pois o chorume contamina o solo (P5).

O esgoto que está a céu aberto e o saneamento básico que é precário. Muitos não têm noções de limpeza e conscientização de que a preservação é a melhor maneira de conservar o ambiente ao qual vive (P8) (RELATÓRIO DE TRANSCRIÇÃO, 2018, p. 81).
\end{abstract}

Desse modo, é possível perceber que o lixo não é visto somente como um problema de caráter ambiental, mas também de saúde e qualidade de vida, como se percebe no discurso dos professores esse problema afeta diretamente a população dessa comunidade.

É possível perceber o lixo exposto e queimado em vários locais, tanto próximo às residências como até mesmo da escola. Assim, nota-se que, em geral, as pessoas não têm consciência a respeito dos problemas que poderão surgir a partir dessa atitude incorreta, além de causar uma má aparência da comunidade, esteticamente, pode contribuir para a proliferação de doenças e servir de esconderijos para animais peçonhentos, o que acaba colocando em risco a vida dos alunos e da população em geral.

Mediante as respostas dos professores, pode-se destacar que na comunidade não existe saneamento básico, sendo possível perceber que os lixos são descartados de forma incorreta. Desse modo, o sistema de saneamento básico torna-se um elemento muito importante para manter a preservação ambiental e, consequentemente, a qualidade de vida de uma população, contudo, além de configurar em um meio de prevenção contra a proliferação de doenças. 
Visando manter a saúde e o bem-estar de toda sociedade brasileira, o saneamento básico tornou-se um direito assegurado pela Constituição e definido pela Lei $\mathrm{n}^{\circ} 11.445$ (BRASIL, 2007), responsável por fornecer serviços de abastecimento de água potável, esgotamento sanitário, drenagem, limpeza urbana e manejos de resíduos sólidos e de águas pluviais. Portanto, falta infraestrutura para que a comunidade possa se desenvolver sem comprometer a saúde de seus habitantes.

Ainda por meio de relatos dos professores, não existe rede de abastecimento de água encanada tratada, a água fornecida para a população é coletada através de poço artesiano, além disso, falta pavimentação nas ruas, onde podemos perceber o esgoto a céu aberto.

Diante disso, percebe-se que de modo geral, os investimentos em relação aos serviços de saneamento básico, ainda são muito precários, o poder público praticamente não investe recursos em saneamento básico nessa comunidade, o que provoca sérios problemas socioambientais.

Outros problemas que se destacam são o desmatamento e as queimadas, que estão sendo realizadas de forma inconsequente, visto que a comunidade é composta por pequenos fazendeiros que desmatam e queimam a floresta para criação de pastos para o gado.

Além disso, algumas áreas são desmatadas por pequenos agricultores que também utilizam essa técnica de desmatamento para a produção agrícola, como mandioca, melancia, banana, abacaxi, dentre outros que servem de meio para subsistência de seus familiares.

Essa prática ainda é muito vivenciada na comunidade Cristolândia, tanto nas pequenas propriedades como nas grandes fazendas que estão localizadas ao longo da BR-319. É notório o processo de queimadas, em larga escala, ao longo da rodovia, ocasionando sérios problemas de saúde para toda a população. Como a escola encontra-se localizada muito próxima da rodovia, nos períodos em que as queimadas são constantes a fumaça causa grande desconforto durante o período de funcionamento da escola.

Outro aspecto muito importante a ser destacado está relacionado com o aumento do tráfego na rodovia, em decorrência da abertura do novo porto graneleiro localizado em Humaitá-AM. Ao analisar a construção do porto e da nova estrada que ligará a BR-319, a princípio parece ser uma evolução para o desenvolvimento econômico de Humaitá, porém pelo fato de aumentar o tráfego na rodovia, essa construção gera muitas preocupações à medida que será intenso o fluxo de carros, caminhões e carretas que serão utilizados para o escoamento da produção proveniente dos estados do Mato Grosso e Rondônia, como por exemplo, soja e outros produtos em geral.

Conforme o exposto na Lei ${ }^{\circ}$ 9.605, que trata de crimes ambientais (BRASIL, 1998), a construção dessa via acarretará sérios problemas ambientais para a população humaitaense e pessoas que residem próximas ao local, como por exemplo: poluição do ar, desmatamento, extinção de animais, entre outros considerados crimes relacionados ao meio ambiente.

\subsubsection{Categoria 2 - Sustentabilidade}

A categoria sustentabilidade foi estabelecida com o objetivo de compreender como os professores entendem a sustentabilidade dentro do contexto da sociedade brasileira. Sabe-se que não cabe apenas ao professor a tarefa de tentar construir uma cidadania com mais responsabilidade social, mas é inegável que a escola pode desempenhar papel importante nesse processo, pois deve proporcionar aos alunos uma reflexão crítica dos fatores econômicos, sociais e políticos que permeiam o uso dos recursos naturais, tanto em relação à extração da matéria-prima, como relativo ao comportamento humano no que diz respeito ao consumo.

Diante dos elevados índices de danos causados à natureza, estudiosos de diversas partes do mundo apontam para a destruição da vida no planeta Terra. Assim, é necessário repensar um novo modelo de produção capaz de manter um equilíbrio ecológico, procurando estabelecer 
uma nova forma de consumo, em que a relação do homem-natureza possibilite a sobrevivência do planeta Terra.

Corrobora-se com a tese de que a escola se estabelece como um instrumento ideológico do Estado, que, na visão de Althusser (1985), a escola passou a ocupar o lugar de espaço dominante, pois é responsável pela educação de crianças em diversas idades e classes sociais, tanto no que diz respeito aos aspectos morais e cívicos quanto ao conhecimento de leituras, cálculo, escrita etc. Assim, a escola desempenha um papel importantíssimo na formação dos indivíduos e da sociedade.

A problemática da educação brasileira é mais pertinente quando se refere à educação do campo, visto que muitos desconhecem e distanciam-se da realidade do cotidiano do campo onde poucos se preocupam com melhorias, sendo que esta ainda é muito carente em relação às políticas públicas voltadas para o atendimento das necessidades culturais, humanas e sociais dessa classe de trabalhadores rurais (RAMOS et al., 2021).

A escola serve para disseminar as propostas estabelecidas no âmbito político e econômico, ou seja, "a educação se subordina a interesses e processos econômicos, políticos e culturais globais externos a ela" Pansardi (2011, p. 136), nesse sentido, a escola não é neutra.

Durante as entrevistas, indagou-se sobre o entendimento do que seria desenvolvimento sustentável para os professores, procurando entender como os mesmos apresentam suas ideias diante dessa proposta de desenvolvimento. Assim, responderam:

\footnotetext{
Acredito que é tudo aquilo tirado da natureza, de alguma outra forma tem que voltar para ela, com isso uma das formas é a reciclagem tirando todo esse lixo e de alguma forma trabalhando para ser utilizado de maneira adequada (P4).

Reutilizar objetos que seriam descartados (P6).

É reutilizar os recursos naturais, por exemplo, reutilizar água para regar as plantas, usar energia solar (P7).

Reflorestamento, reciclagem, coleta seletiva (P8) (RELATÓRIO DE TRANSCRIÇÃO, 2018, p. 79).
}

Como se constatou, os professores ainda relacionam muito o desenvolvimento sustentável à questão do reutilizar, reciclar, reflorestar. Não foi possível identificar uma fala questionando o modo de produção da sociedade brasileira, o que demonstra que os professores não conseguem atrelar as relações sociais, econômicas e políticas ao tipo de desenvolvimento que se encontra presente no Brasil.

A sustentabilidade é um processo que deve ser estabelecido em longo prazo, pois é fato que, para haver um desenvolvimento sustentável é necessário trocar o atual e predominante modelo de desenvolvimento - o capitalista-industrial. Há necessidade de construir uma modalidade de desenvolvimento que priorize, na letra e na prática, a sustentabilidade, considerando o pleno e conjunto desenvolvimento dos seres humanos, dos animais, das plantas, de todo o planeta Terra (RAMOS et al., 2019).

Quando se questionou sobre as suas atitudes em relação à natureza, os professores demonstraram um grau de consciência ambiental, mas, novamente, as respostas dadas não permitem depreender que entendem que os problemas ambientais também são problemas políticos e econômicos:

Separação do lixo e a reciclagem de objetos como vidros, papel e plásticos (P6). Fazendo a coleta correta do lixo. Não desperdiçar água. Economizar energia. Fazer uso de materiais reciclados (P7).

Coletar o lixo, evitando queimar o lixo doméstico fora de hora e enterrar (P8).

Para a conservação do meio ambiente não depende só de mim e da minha família. Depende de todos nós, essas atitudes têm de ser seletiva mantendo em conservação o meio em que vive, não jogando lixo nos rios e igarapés, limpeza nos quintais, 
mantendo-o a sua própria casa limpa e arejada (P1) RELATÓRIO DE TRANSCRIÇÃO, 2018, p. 80).

O grau de desenvolvimento da consciência ambiental irá incidir diretamente no comportamento do sujeito diante das questões ambientais, de modo geral. Como se pôde verificar, os professores expuseram uma preocupação muito imediatista da problemática da questão ambiental, relacionado sempre com a reciclagem, queimada, economia de energia etc. Esses aspectos são importantes, não restam dúvidas, mas é necessário aprofundar o debate e a reflexão sobre essa problemática, objetivando construir uma verdadeira consciência ambiental crítica.

Com relação ao futuro das novas gerações no planeta Terra, os professores demonstraram uma preocupação imediatista com o meio ambiente, com os animais, com os rios etc. Não se identificou uma consciência ambiental crítica, capaz de contextualizar os homens e mulheres no processo de produção que aponta para o consumo e o lucro.

No contexto das interpretações com base nas respostas dos professores, contudo, há que se enfatizar que estes, enquanto profissionais da educação, não estão recebendo formação adequada para trabalhar essa temática, mas, ainda assim, existe uma preocupação dos professores com as questões ambientais vivenciadas no seu cotidiano.

\subsubsection{Categoria 3 - Educação}

Essa categoria está relacionada com as questões ambientais e a educação, considerando que a proposta desta pesquisa consistiu em analisar a percepção ambiental dos professores e suas relações com o processo educativo.

A temática ambiental deve ser abordada de forma transversal em todos os componentes curriculares da escola, conforme estabelece o Conselho Nacional de Educação, através da Resolução n $^{\text {2 }}$, de 15 de junho de 2012 (BRASIL, 2012b).

Nessa categoria, percebeu-se a dificuldade dos professores de abordar, de forma adequada, a questão ambiental no contexto escolar. Perguntados se relacionam à temática meio ambiente, durante suas aulas, estes responderam:

\footnotetext{
Dificilmente, o sistema de ensino é muito carente de recursos didáticos. Até mesmo quando relaciona algum assunto me preocupo em fazer a associação ao dia-a-dia do educando (P2).

Sim, não todos os dias, mas em conteúdos curriculares como: meio ambiente, dia da árvore, seres vivos e não vivos... Sempre que se tem oportunidades, discuto com os alunos sobre o assunto. Fazemos atividades pedagógicas relacionadas ao tema para melhor compreensão (P3).

Na realidade não. Trabalho com a disciplina de língua portuguesa, mas não lembro de ter trabalhado, porém é muito importante abordar temas ligados ao meio ambiente (P4).

Sim, nas aulas de história, geografia o meio natural pode ser visto mais intensidade (P5) (RELATÓRIO DE TRANSCRIÇÃO, 2018, p. 82).
}

Os professores apontaram que tem dificuldades para trabalhar a temática, seja por conta de recursos pedagógicos insuficientes, seja por não compreenderem que a temática deveria ser trabalhada na perspectiva interdisciplinar. Cabe à SEMED, como órgão público responsável pelo atendimento às escolas no município de Humaitá-AM, sejam elas urbanas ou rurais, fornecer o suporte básico que os professores necessitam para desenvolverem seus trabalhos nas escolas. Nesse sentido, Souza; Lima (2019, p.162-167) ressalta que: "os recursos didáticos no processo de ensino-aprendizagem motivam o interesse do aluno pela disciplina".

Mediante a fala do autor, nota-se que os materiais didáticos são instrumentos importantes, que servem para nortear o trabalho do professor, possibilitando, assim, o 
desenvolvimento de técnicas e metodologias diferenciadas que podem contribuir para o bom desempenho dos alunos.

Outra indagação realizada diz respeito à participação dos professores em programas direcionados à proteção ambiental, todos os professores afirmaram nunca terem participado de nenhum tipo de formação.

Nunca participei de nenhum programa desse tipo, seria importante para conscientizar a comunidade (P4).

Não, nunca (P5).

Não tive o privilégio (P6) (RELATÓRIO DE TRANSCRIÇÃO, 2018, p.83).

Percebeu-se que os professores consideram importante a formação, mas atribuem a responsabilidade apenas à SEMED, sem considerar que a formação é um ato político e, portanto, deve perpassar pelo compromisso do professor com as temáticas emergentes na sociedade. Considerando que a temática ambiental se encontra em voga, em diversos formatos de informação como a internet, que disponibiliza diversos sites apresentando pesquisas, projetos e artigos científicos, não seria muito difícil os professores se apropriarem de conhecimento sobre a temática ambiental.

Em relação à formação, Sato $(2001$, p.16) enfatiza que " [...] a carência da introdução da Educação Ambiental (EA) nos currículos de graduação, pós-graduação e cursos de formação continuada é fortemente presente no cenário nacional e em muitos outros países latinoamericanos".

A Escola Municipal Antonieta Ataíde II não proporciona aos professores materiais adequados para desenvolver um trabalho de qualidade, seja em relação à temática ambiental e/ou em outros contextos, pois a falta de recursos didáticos pedagógicos foi muito enfatizada por esses profissionais.

\footnotetext{
As dificuldades encontradas mais frequentes são: falta de apoio das instituições regionais que dizem ser os responsáveis pela preservação ambiental (P1).

Falta de livros didáticos e recursos para se utilizar nas aulas (P2).

Às vezes faltam recursos do tipo áudio visuais. Isso entra como dificuldade em função da escola ser pouco assistida (P5).

Falta de recursos e capacitação na área (P7) (RELATÓRIO DE TRANSCRIÇÃO, 2018, p. 85).
}

Percebe-se, diante da fala dos professores, que há a necessidade de valorização em relação à educação do campo, pois são várias as dificuldades enfrentadas pelos docentes e alunos. Dessa forma, pode-se afirmar que sem o apoio e a colaboração da instituição será muito difícil desenvolver uma prática educativa que torne o processo de ensino-aprendizagem satisfatório e que proporcione ao aluno se reconhecer como sujeito ativo desse processo, relacionando as práticas pedagógicas às problemáticas vivenciadas em seu cotidiano.

Os professores afirmam que até recebem informações sobre a temática, mas não existem ações que possam ajudá-los na preparação e execução de atividades pedagógicas. Como se verifica nas afirmações abaixo:

Em termos de orientação e informação estão sim (P3).

Acredito que não, a escola até informa, porém não vejo programas relacionados a isso. Precisa mais projetos principalmente na zona rural (P4).

A preservação dos recursos entra nas aulas de conteúdo específico ligado ao tema (P5) (RELATÓRIO DE TRANSCRIÇÃO, 2018, p.86).

Ainda há um entendimento por parte dos professores sobre a forma de trabalhar a questão ambiental numa perspectiva interdisciplinar. Mas, devemos enfatizar que a SEMED 
tem contribuído muito pouco na formação continuada e, mesmo, no acompanhamento e orientação pedagógica no desenvolvimento da prática dos professores. Isso pode acarretar graves problemas no processo educativo, pois planejar, organizando a ação educativa, é oferecer um clima que favoreça o processo de construção do conhecimento, olhando para os objetivos que se pretende alcançar, o potencial didático da equipe escolar, as estratégias utilizadas, os recursos e etapas a serem percorridas (PIMENTA, 2008, p.7).

Assim como em outros municípios do estado do Amazonas, é comum ouvir falar sobre a precariedade no sistema de ensino público. Além da falta de atendimento adequado as escolas do campo, outro fator que se destaca é a falta de valorização do profissional que atua na educação básica, que recebe o mesmo piso salarial que os professores urbanos.

Os professores necessitam de condições adequadas para efetuarem seus trabalhos, incluindo a formação e qualificação para atuar no campo e na Educação básica. No que diz respeito à formação docente, de acordo com o que foi estabelecido pelo Plano Nacional de Educação - PNE (MEC, 2000, p. 77) "a melhoria da qualidade do ensino, indispensável para assegurar à população brasileira o acesso pleno à cidadania e a inserção nas atividades produtivas que permita a elevação constante do nível de vida, constitui um compromisso da Nação".

As exigências para trabalhar na área da educação são bem claras, conforme exposto acima, porém o que se percebe na maioria das vezes, no município de Humaitá-AM, em comunidades ribeirinhas, são professores atuando em salas multisseriadas e que apresenta em sua formação, apenas o ensino fundamental e médio, fato que ocasiona um índice negativo no processo de aprendizagem dos alunos.

Ao indagar os professores sobre o papel da escola em relação ao meio ambiente é possível verificar que todos reconhecem a importância da escola na formação da consciência ambiental de seus alunos:

\footnotetext{
O papel da escola com relação ao meio ambiente é uma prática inovada no campo da educação, pois determina a importância do conhecimento para a formação de cidadãos conscientes e responsáveis. O conhecimento ambiental só faz sentido quando o educador correlaciona as informações com a realidade social e econômica do aluno (P1).

O papel da escolar é muito importante para o meio ambiente e através desta que se deve conscientizar as pessoas sobre a importância do meio ambiente, usar ideia de prevenir contra a degradação do meio ambiente, usar ideia de prevenir contra a degradação do meio ambiente (P8).

De fundamental importância. Pois só conscientizando as gerações atuais pra que o futuro possa ter uma vida de qualidade (P6).

Primeiro incluir projetos que desenvolva essa preocupação já pensando nas futuras gerações. Conscientizar e desenvolver hortas comunitárias, realizar plantio de mudas próximo à escola (P2).

A meu ver a escola deveria criar projetos que envolva os alunos incentivando os mesmos a preservar o meio ambiente e cuidar da natureza (P7) (RELATÓRIO DE TRANSCRIÇÃO, 2018, p.87).
}

A EA deve ser uma proposta de trabalho pedagógico da escola como ação transformadora, crítica e política, pois contextualizar o uso dos recursos naturais, a apropriação e exploração desses recursos vão além da retirada desse material da natureza, encontra-se ligada a percepção que o homem possui diante do modo de produção capitalista, onde o consumo é incentivado para a geração de lucros, a qualquer preço, mesmo que isso esteja colocando em risco a sobrevivência da espécie humana no planeta Terra.

De acordo com Leff (2012, p. 37), o saber ambiental: 
[...] se caracteriza pela busca de novas matrizes de racionalidade que abrem espaço aos sentidos não formalizáveis; ao incomensurável, ao diverso e ao heterogêneo. Leva a um diálogo e amálgama de saberes, incluindo os níveis mais elevados de abstração conceitual até os níveis do saber prático e cotidiano, onde se manifestam suas estratégias e práticas.

Além disso, desde a Conferência de Estocolmo em 1972 sobre o ambiente humano (PEDRINI, 2002) a Educação Ambiental foi formalmente citada num Tratado de implicações internacionais. Posteriormente, o diálogo entre os educadores ambientais do mundo promoveram conferências internacionais específicas em EA, como as de Tbilisi, Belgrado e Moscou, fortalecendo ainda mais as práticas voltadas ao meio ambiente. De toda essa movimentação dos educadores e ambientalistas derivando uma maior visibilidade para a Educação Ambiental no Brasil (PEDRINI, 2006).

É necessária uma formação que possibilite ao professor refletir criticamente sobre os saberes escolares para uma prática educativa mais elaborada e adequada ao tematizar o ambiente, pois a EA deve ser trabalhada de forma que permita tanto ao professor quanto ao aluno desenvolver ações para diminuir os efeitos predatórios das relações dos sujeitos com a natureza, objetivando assim a construção de uma sociedade sustentável do ponto de vista socioambiental.

Nesse sentido, a EA pode favorecer mudanças significativas nas ações humanas em relação ao meio ambiente, tentando diminuir a crescente degradação socioambiental vivenciada nos dias atuais, pois a EA pode-se converter em "mais uma ferramenta de mediação necessária entre culturas, comportamentos diferenciados e interesses de grupos sociais para a construção das transformações desejadas" (TAMAIO, 2000, p. 38).

Reigota (1999) apresenta três categorias de representação do meio ambiente, que são: Globalizante: demonstra as relações recíprocas entre natureza e sociedade; Antropocêntrica: privilegia o uso dos recursos naturais para a sobrevivência do homem; Naturalista: demonstra somente os aspectos naturais do meio ambiente.

Dessa forma, pode-se identificar que a percepção ambiental dos professores da Escola Municipal Rural Antonieta Ataíde II se apresenta, em grande parte, numa perspectiva mais naturalista, segundo Reigota (1999). Porém, é necessário salientar que esses professores apresentam um grau de consciência ambiental, reconhecem a importância da educação na transformação da sociedade brasileira, conforme foi apresentado nas categorias acima.

\section{Considerações Finais}

De acordo com os dados levantados, verificou-se que há uma relação de saberes entre os educadores do campo com a comunidade local que está diretamente ligada a educação escolar e as questões ambientais. Entende-se que esses saberes são de cunho socioeconômico, político, social e demográfico.

No entanto, através do processo educativo será possível construir novos conhecimentos, onde esses saberes deverão estar voltados para atender às necessidades específicas e contribuir, significativamente, para o processo de mudança de comportamento das pessoas, despertando, assim, uma consciência crítica e responsável em relação ao meio ambiente.

Nesse sentido, os professores necessitam ampliar seus conhecimentos e reflexões em relação aos danos causados por essas ações negativas que causam agressões ao meio ambiente local, pois, somente assim, poderá desenvolver juntamente com os alunos e comunidade um trabalho significativo, promovendo atitudes positivas que possam contribuir para diminuir os impactos causados ao meio ambiente e, consequentemente, à qualidade de vida das pessoas dessa comunidade. Além disso, destaca-se que o estudo sobre a percepção ambiental poderá sensibilizar os professores e demais membros da comunidade, despertando, assim, um olhar 
crítico voltado para a preservação e conservação do meio ambiente, assegurando o direito das futuras gerações a um ambiente que proporcione melhor qualidade de vida, ou seja, uma postura cidadã comprometida com valores sustentáveis, ecológicos e sociais.

Nesta perspectiva a percepção que temos é que ao longo do tempo, a evolução da humanidade acarretou uma série de problemas de cunho socioambiental, gerando impactos negativos que incidiram diretamente sobre os recursos naturais e no modo de vida da sociedade de forma geral. É nesse contexto que emerge a necessidade de defender o meio ambiente, ou seja, lutar para diminuir o acelerado ritmo de destruição dos recursos naturais, buscando alternativas que possam conciliar na prática a conservação da natureza com a qualidade de vida dos indivíduos (RAMOS et al., 2021).

Portanto, o estudo sobre a percepção dos educadores do campo em relação ao meio ambiente, no qual estão inseridos, foi importante, também para ampliar a compreensão sobre como as práticas pedagógicas estão abordando a temática meio ambiente, numa perspectiva de consciência ecológica.

\section{Agradecimentos}

Aos revisores e colaboradores e à Fundação de Amparo à Pesquisa do Estado do Amazonas (FAPEAM), Coordenação de Aperfeiçoamento de Pessoal de Nível Superior (CAPES) pela concessão de bolsas científicas para as duas primeiras autoras.

\section{Referências}

ALTHUSSER, L. Aparelhos Ideológicos de Estado: nota sobre os aparelhos ideológicos de estado (AIE). 2 ed. Tradução de Walter José Evangelista e Maria Laura Viveiros de Castro. Rio de Janeiro: Edições Graal, 1985.

BEZERRA, D.R.S.; SILVA, A.P.S. Educação do Campo: apropriação pelas professoras de uma escola de assentamento. Psicologia Escolar e Educacional, Maringá, v. 22, n. 3, p. 467-475, 2018.

BONI, V.; QUARESMA, S.J. Aprendendo a entrevistar: como fazer entrevistas em Ciências Sociais. Revista Eletrônica dos Pós-Graduandos em Sociologia Política da UFSC, Florianópolis, v. 2, n. 1, p. $68-80,2005$

BRASIL. Lei ${ }^{\circ}$ 9.605, de 12 de fevereiro de 1998. Dispõe sobre sanções penais e administrativas derivadas de condutas e atividades lesivas ao meio ambiente, e dá outras providências. Brasília: Casa Civil, 1998. Disponível em: <http://www.planalto.gov.br/ccivil_03/leis/19605.htm〉. Acesso em 15 jun. 2021.

BRASIL. Lei 11.445, de 5 de janeiro de 2007. Estabelece as diretrizes nacionais para o saneamento básico... Brasília: Casa Civil, 2007. Disponível em: <http://www.planalto.gov.br/ccivil_03/_ato20072010/2007/lei/L11445compilado.htm>. Aceso em: 15 jun. 2021.

BRASIL. Ministério da Saúde. Resolução CNS 466, de 12 de dezembro de 2012. Brasília: CNS, 2012a. Disponível em: <https://conselho.saude.gov.br/resolucoes/2012/Reso466.pdf>. Acesso em: 15 jun. 2021.

BRASIL. Ministério da Educação. Resolução CNE/CP n², de 15 de junho de 2012. Estabelece as Diretrizes Curriculares Nacionais para a Educação Ambiental. Brasília: MEC/CNE, 2012b. Disponível em: < http://portal.mec.gov.br/dmdocuments/rcp002_12.pdf>. Acesso em: 15 jun. 2021. 
CARVALHO, A. M. P.; GIL-PÉREZ, D. Formação de professores de ciências: tendências e inovações. São Paulo: Cortez, 2011.

FÁVERO, M.H.; NEVES, R.S.P. A docência universitária como lócus de pesquisa da psicologia do desenvolvimento adulto. Revista Semestral da Associação Brasileira de Psicologia Escolar e Educacional, Maringá, v. 17, n. 2, p.319-328, 2013.

LEFF, E. Saber Ambiental: sustentabilidade, racionalidade, complexidade, poder. 9 ed. Petrópolis: Vozes, 2012.

MEC - Ministério da Educação. Plano Nacional da Educação. Brasília: MEC/FNDE/SEED, 2000. Disponível em: < http://portal.mec.gov.br/arquivos/pdf/pne.pdf>. Acesso em: 15 jun. 2021.

MORAES, R.; GALIAZZI, M.C. Análise Textual Discursiva: processo constitutivo de múltiplas faces. Ciência \& Educação, Bauru, v. 12, n. 1, p. 117-128, 2016.

OLIVEIRA, B.O.S.; TUCCI, C.A.F.; NEVES-JÚNIOR, A.F.; SANTOS, A.A. Avaliação dos solos e das águas nas áreas de influência de disposição de resíduos sólidos urbanos de Humaitá-AM.

Engenharia Sanitária Ambiental, Rio de Janeiro, v. 21, n. 3, p. 593-206, 2016.

PANSARDI, M.V. A formação de professores e o Banco Mundial. EccoS Rev. Cient., s.v, n. 25, p. 127-142, Ene./Jun. 2011. Disponível em: < https://www.redalyc.org/pdf/715/71521708008.pdf>. Acesso em: 15 jun. 2021.

PEDRINI, A de G. Trajetórias em Educação Ambiental. In: PEDRINI, A de G. (Org.). Educação Ambiental: reflexões e práticas contemporâneas. 5 ed., Petrópolis: 2002. Inserir p. 115-120.

PEDRINI, A de G. A educação ambiental com a biodiversidade no Brasil: um ensaio. Ambiente \& Educação, Rio Grande, v. 11, n. 1, p.63-77, 2006.

PIMENTA, S.A. Didática e o ensino de geografia. Campina Grande: EDUEP, 2008.

RAMOS, A.S.; FONSECA, P.R.B.; NOGUEIRA, E.M.L.; LIMA, R.A. A Relevância da educação ambiental para o desenvolvimento da sustentabilidade: uma breve análise. Revista Gestão \& Sustentabilidade Ambiental, Florianópolis, v. 8, n. 4, p. 30-41, 2019.

RAMOS, A.S.; NOGUEIRA, E.M.L.; LIMA, R.A. A concepção de educadores do campo sobre meio ambiente: uma breve análise. South American Journal of Basic Education, Technical and Technological, Rio Branco, v.8, n.1, p.388-406, 2021.

REIGOTA, M. Ecologia, elite e inteligência na América Latina: um estudo de suas representações sociais. São Paulo: Annablumme/WWF, 1999.

RODRIGUES, P.S.; EICKHOFF, A.P.N. Percepção ambiental: análise das concepções de alunos do $6^{\circ}$ ano de uma escola pública de Sorriso-Mato Grosso. Revista Prática Docente, v.5, n.3, p.1786-1801, 2020.

SATO, M. Debatendo os desafios da educação Ambiental. Revista Brasileira De Educação Ambiental, São Paulo, v.5/6, n.1, p. 14-33, 2001.

SOUSA, R.S.; GALIAZZI, M.C. A categoria na análise textual discursiva: sobre método e sistema em direção à abertura interpretativa. Revista Pesquisa Qualitativa, São Paulo, v. 5, n. 9, p. 514-538, 2017. 
SOUZA, M.G.P.; LIMA, R.A. A vivência do estágio supervisionado e as contribuições do PIBID para a formação dos licenciandos em Ciências: Biologia e Química. Revista Iniciação \& Formação Docente, Uberaba, v.6, n.1, p.154-167, 2019.

TAMAIO, I.A. A mediação do professor na construção do conceito da natureza. 2000. $141 \mathrm{f}$. Dissertação (Mestrado em Educação) - Universidade de Campinas, Faculdade de Educação, Campinas, 2000.

TOZONI-REIS, M.F.C.; CAMPOS, L.M.L. Educação ambiental escolar, formação humana e formação de professores: articulações necessárias. Educar em Revista, Curitiba, v. 30, n. especial 3, p.145-162, 2014. 